\title{
Size Miniaturized Coaxial Probe Fed Antenna for Multiband Applications
}

\author{
Bahareh Heydarpanag ${ }^{1}$, Changiz Ghobadi ${ }^{1}$, Javad Nourinia ${ }^{1}$, \\ Payam Beigi $^{2}$, and Maryam Majidzadeh ${ }^{3}$
}

\author{
${ }^{1}$ Electrical Engineering Department, Urmia University, Urmia, Iran \\ ${ }^{2}$ Young Researchers and Elite club, Urmia Branch, Islamic Azad University, Urmia, Iran \\ ${ }^{3}$ Department of Electrical and Computer Engineering, Urmia Girls Faculty, West Azarbaijan branch, Technical and Vocational \\ University (TVU), Urmia, Iran \\ *corresponding author, E-mail: mmajidzadeh@tvu.ac.ir
}

\begin{abstract}
A coaxial cable-fed antenna with a combination of Lshaped elements is proposed for multiband applications. The obtained resonances at different frequency bands are realized by adding L-shaped strips with different lengths to the antenna geometry. The antenna is printed on a lowpriced FR-4 substrate with overall size of $14 \times 14 \times 1.6 \mathrm{~mm}^{3}$. Experimental results indicate the coverage of 1.32, 1.80, 2.34, 3.30, 3.66, 4.26, 5.28, 7.68, 8.1, 9.72 and $10.38 \mathrm{GHz}$, compatible with L-band, WLAN, WiMAX, C-band, ITU 8 $\mathrm{GHz}$, and X-band. Suitable radiation properties, multiband functionality, desirable gain values and agreement of simulated and measured results confirm the suitability of the proposed structure for multiband communication applications.
\end{abstract}

\section{Introduction}

Paving the way to accommodate the rapid development of wireless communication calls the need for antennas with multiband performance. To this end, a vast variety of researches have been conducted on design of antenna structures with more than one operating band [1-9]. Being able to operate in multi frequency bands, this category of antennas has gained popularity in different applications. For instance, regarding the smartphones and mobile phones applications, the proposed antenna structure in [1] is composed of a monopole antenna and a coupled ground line which is developed for global system for mobile (GSM) communication and long-term evolution (LTE) in different service bands of 900, 1800, 1900, 2300, and $2500 \mathrm{MHz}$. The very compact antenna in [2] is a folded loop antenna for ultra-thin smart phone applications. Four resonant modes are excited for GSM850, GSM900, DCS1800, PCS1900, UMTS, TD-SCDMA, LTE2300, and WLAN systems. In addition, the author in [3] have surveyed an antenna topology composed of two symmetrical radiating elements connected by neutralizing line to cancel the reactive coupling. The radiating element which is composed of folded monopole and a beveled rectangular metal patch, excited resonances at GSM $900 \mathrm{MHz}$, DCS $1800 \mathrm{MHz}$, LTE-E $2300 \mathrm{MHz}$, and LTE-D $2600 \mathrm{MHz}$. Laptop computers are the other candidates to use multi band antennas [4]. The proposed miniature planar monopole antenna structure in [4] is printed on ceramic substrate. The constituent elements include tuning strip and two distinct pairs of driven and coupled strips. By the aforementioned structure, pentane-band wireless wide area network (WWAN) applications are envisaged for the antenna. A wide variety of WLAN frequency band applications are seen among the studied conducted on multi band antenna [5-8] which include different frequency ranges of WLAN in their operating frequency bands. Moreover, Fractal structures have also been used to generate multi band operation. For instance, crinkle fractal-structure is adopted in [9] to yield a triple-band operation. In [10], a hybrid design of a microstrip-fed parasitic coupled ring fractal monopole antenna with semi-ellipse ground plane is proposed for WLAN and WiMAX applications. Also, other applications could be found in [11-15]. Although interesting outcomes have been reported in the case of recently published and reviewed antenna structures, improving the multiband antennas features in terms of size miniaturization, frequency bands extension, and the compatibility of the obtained frequency bands with applicable and in-service frequency ranges calls the need for further investigations on this context. With the aim of proposing a reliable and efficient antenna design, a compact antenna geometry with L-shapedelements is proposed for L-band/WiMAX/WLAN/C-band/ ITU $8 \mathrm{GHz}$ and $\mathrm{X}$-band applications. The main radiating patch of the proposed design consists of several L-shaped elements. Each constituent L-shaped element is responsible for exciting a resonance; thus, by including different Lshaped elements with different lengths, multi resonances are appeared which yields a multiband performance. The obtained results indicate that impedance bandwidths of 230 $\mathrm{MHz}$ (1.19-1.42 GHz), $280 \mathrm{MHz}$ (1.70-1.98 GHz), 320 $\mathrm{MHz}(2.19-2.51 \mathrm{GHz}), 680 \mathrm{MHz}(3.14-3.82 \mathrm{GHz}), 380$ 
$\mathrm{MHz}$ (4.10-4.48 GHz), $530 \mathrm{MHz}(5.07-5.60 \mathrm{GHz}), 1310$ $\mathrm{MHz}(7.23-8.54 \mathrm{GHz})$ and $1150 \mathrm{MHz}(9.48-10.63 \mathrm{GHz})$ to cover the L-band (1-2 GHz), WLAN (2.4 GHz), WiMAX (3.5 GHz), C-band (4 GHz), WLAN (5.2 GHZ) and some part of 8 to $12 \mathrm{GHz}$ are covered by the proposed design. It is worth noting that suitable gain and radiation characteristics are observed over all of the operating frequency bands.

\section{Antenna design}

The schematic view of the proposed antenna is shown in Figure 1(a). Moreover, the fabricated prototype is shown in Figure 1(b). As mentioned earlier, L-shaped elements with wisely tuned dimensions and positions are adopted as the radiating patches. Being different in width, the L-shaped strips resonate at desired frequencies of applicable frequency ranges, resulting in a multiband performance. A $50 \Omega$ coaxial feed line, which is placed on the upper side of the substrate, is adopted to feed the antenna. The reported antenna is printed on an inexpensive FR4 substrate with overall size of $14 \times 14 \times 1.6 \mathrm{~mm}^{3}$, relative permittivity of 4.4 , and loss tangent of 0.0022 . The optimized values of the antenna parameters are reported in Table 1. The proposed antenna is simulated using Ansoft High Frequency Structure Simulator (HFSS) software and the relevant magnitude of the reflection coefficient is plotted in Figure 2. As can be seen, multi resonances are excited in different frequencies which yield a multi band operation at 1.32, 1.80, 2.34, 3.30, 3.66, 4.26, 5.28, 7.68, 8.1, 9.72 and $10.38 \mathrm{GHz}$, compatible with L-band, WLAN, WiMAX, C-band, ITU $8 \mathrm{GHz}$, and X-band.

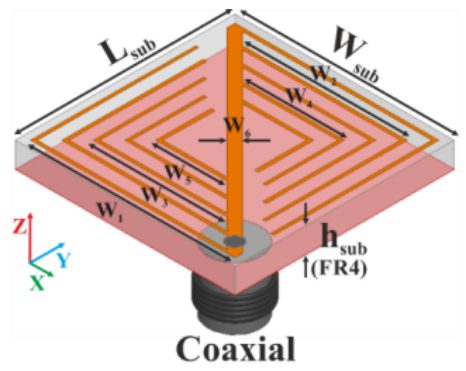

Feed Line

(a)

(b)

Figure 1: Geometry of the proposed antenna (a) antenna configuration, (b) fabricated prototype, (c) antenna in measurement process.

Table 1: The optimized dimensions of the proposed antenna

\begin{tabular}{c|c|c|c|c|c}
\hline $\mathrm{W}_{1}$ & $\mathrm{~W}_{2}$ & $\mathrm{~W}_{3}$ & $\mathrm{~W}_{4}$ & $\mathrm{~W}_{5}$ & $\mathrm{~W}_{6}$ \\
\hline 13 & 10.5 & 8.5 & 6.5 & 4.5 & 0.7 \\
\hline \hline
\end{tabular}

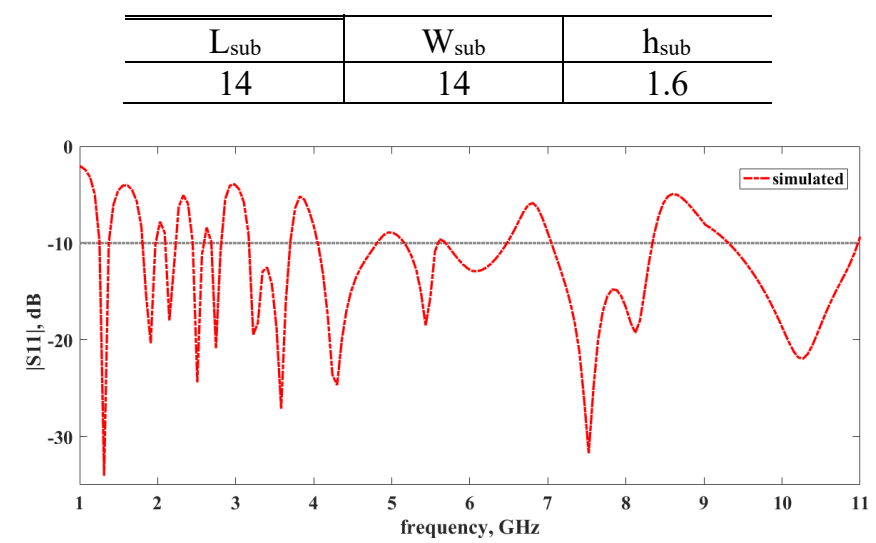

Figure 2: magnitude of the reflection coefficient for the proposed multi band antenna.

To further explain the antenna design process and reveal the role of each L-shaped element on the antenna performance, the proposed antenna configuration is developed in five steps as shown in Figure 3. The corresponding magnitude of the reflection coefficient is plotted in Figure 4 to reveal the effect of including L-shaped elements in each development step. As it is shown, in Ant. 1, two L-shaped elements are included in antenna body. In this case, seven resonances are excited. Then in Ant. 2, by including two other L-shaped elements, other resonances are excited both at lower and higher frequencies. The displacement of the resonances is mainly due to the fact that the inclusion of the second pair of the L-shaped elements creates a coupling effect with the first pair of the L-shaped elements. In the sequel, by the inclusion of the third, fourth, and fifth pair of the L-shaped elements, other resonances are excited which finally yield a multi band operation.

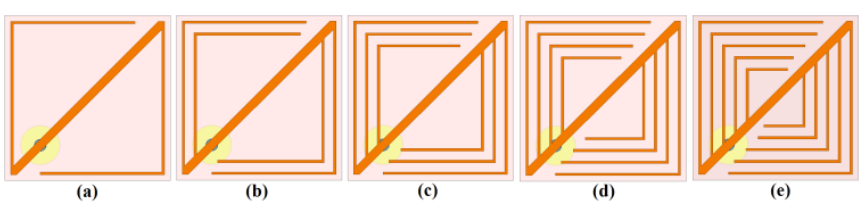

Figure 3: Design process of the proposed multi band antenna. (a) Ant. 1, (b) Ant. 2, (c) Ant. 3, (d) Ant. 4, (e) Ant. 5.

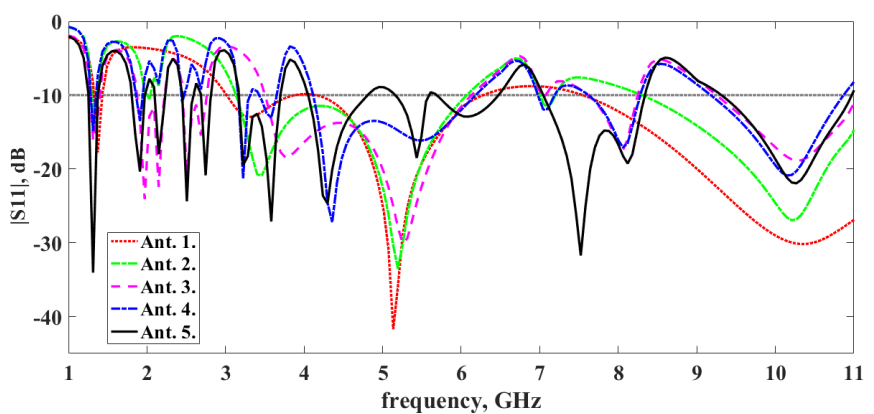

Figure 4: magnitude of the reflection coefficient for the antennas depicted in Fig.3.

Total radiation efficiency of higher than $50 \%$ is observed for Ant. 4, and Ant. 5 that is indicated in Figure 5. Moreover, to clarify the role of each constituent L-shaped strip on the 
antenna performance and multiband performance achievement through other analysis methods, nine surface current distribution plots relating to the nine different resonance frequencies are depicted in Figure 6. As mentioned before, each part of the L-shaped structure in the antenna excites one of the existing resonances. It is a wellknown fact that the elements with red colors refer to the most current carrying parts on the antenna. For instance, the resonance in $5.4 \mathrm{GHz}$, yielding WLAN coverage, is obtained by the shortest L-shaped strips on the antenna. As well, some resonances are obtained by more than one strip, such as the one at $1.86 \mathrm{GHz}$ that is obtained by the two longest Lshaped strips.

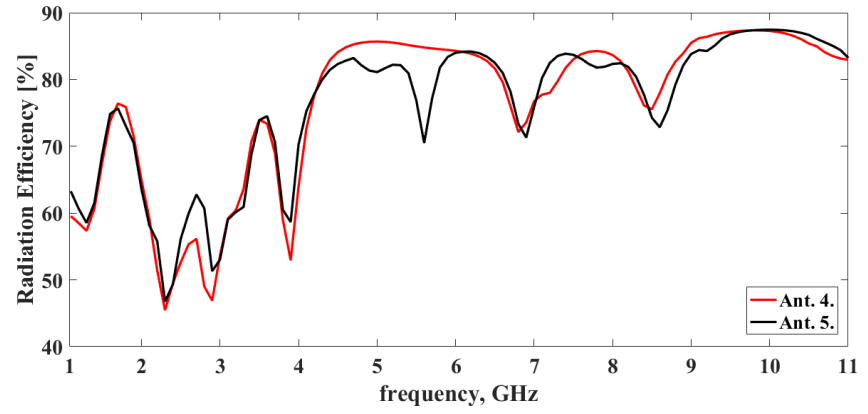

Figure 5: Simulated radiation efficiency of antenna.

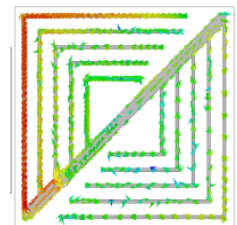

$1.26 \mathrm{GHz}$

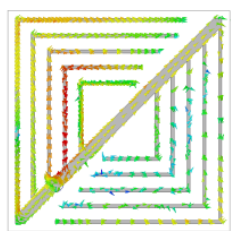

$3.54 \mathrm{GHz}$

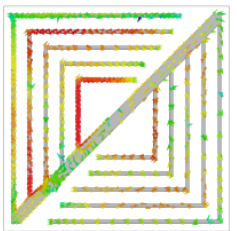

$7.5 \mathrm{GHz}$

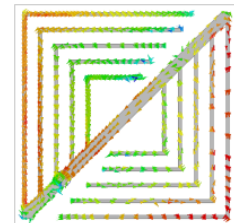

$1.86 \mathrm{GHz}$

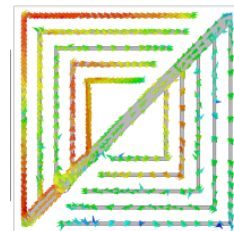

$4.26 \mathrm{GHz}$

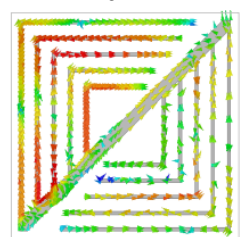

$8.1 \mathrm{GHz}$

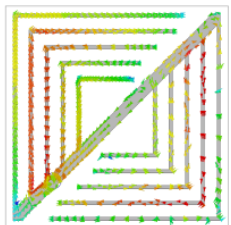

$2.46 \mathrm{GHz}$

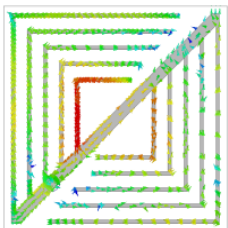

$5.4 \mathrm{GHz}$

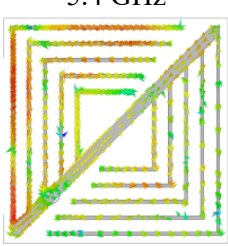

$10.26 \mathrm{GHz}$
Figure 6: Surface current distribution on the antenna at different resonance frequencies.

\section{Results and discussion:}

To validate the obtained results, the fabricated antenna is measured in antenna chamber as shown in Figure 1(c). Simulated and measured magnitude of the reflection coefficient are given in Figure 7. Close agreement of the results confirms the suitable performance of the antenna. As it is clearly shown in Figure 7, both the simulated and measured results can cover L-band, WLAN, WiMAX, C- band, ITU $8 \mathrm{GHz}$, and X-band satellite communication applications. Different frequency bands are highlighted with different colors.

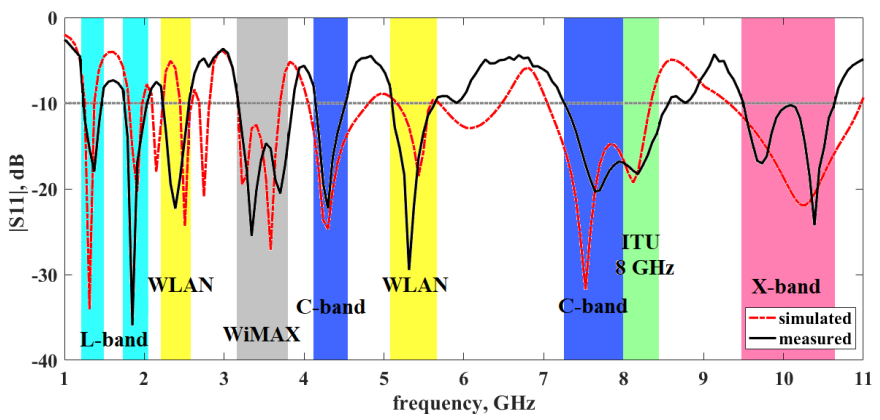

Figure 7: Simulated and measured magnitude of the reflection coefficient for the proposed antenna.

The two-dimensional measured radiation patterns in the $\mathrm{H}$ plane ( $\mathrm{x}-\mathrm{z}$ plane) and E-plane (y-z plane) are shown in Figure 8. Six resonance frequencies are selected as sample frequencies of the operating bandwidths. As can be seen, the radiation patterns at both $\mathrm{H}$-plane and E-plane are almost omnidirectional. Moreover, the obtained simulated and measured peak gain values are depicted in Figure 8. Acceptable results are observed over the operating frequency bands.

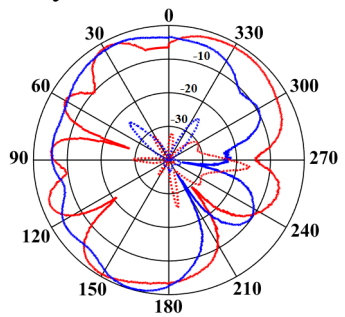

(a)

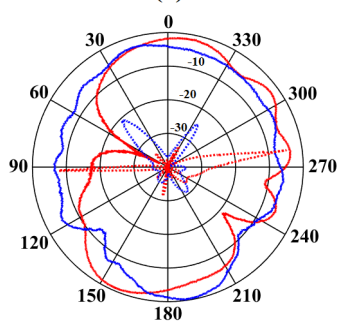

(c)

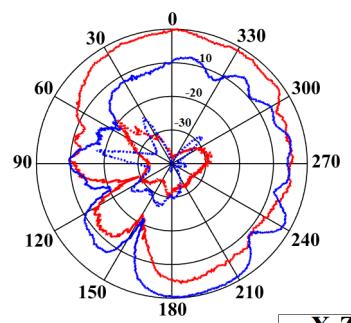

(e)

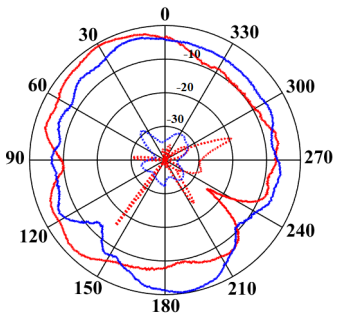

(b)

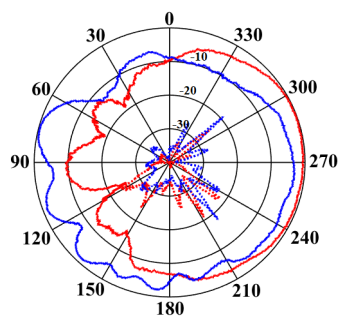

(d)

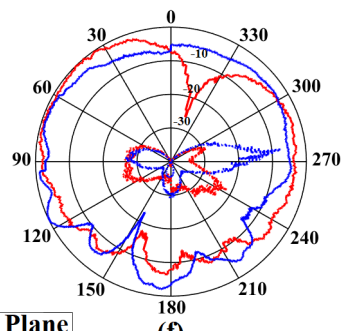

(f)

Figure 8: Measured radiation patterns of the proposed antenna at (a) 1.8 , (b) 2.3, (c) 3.6, (d) 5.2, (e) 8.1, and (f) $10.3 \mathrm{GHz}$ at $\mathrm{x}-\mathrm{z}-\mathrm{Plane}$ and $\mathrm{x}-\mathrm{y}-\mathrm{Plane}$. 


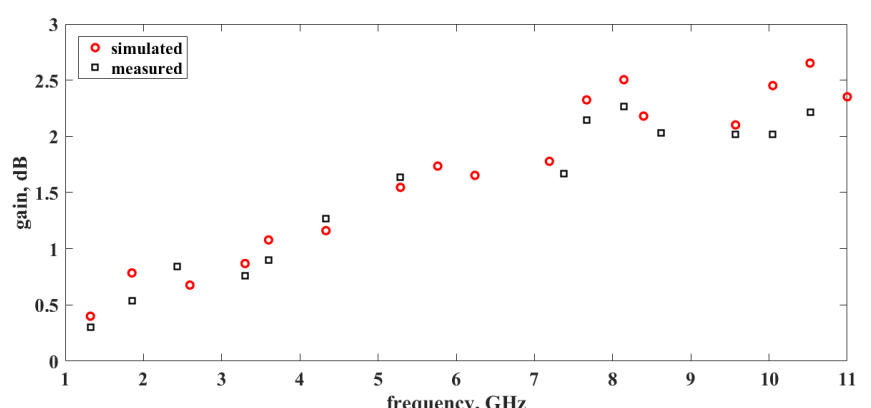

Figure 9: Simulated and measured peak gain for the proposed antenna. small size, by suitable placement of the conductive elements and wise tuning of their dimensions, the proposed design covers the frequency bands of L-band (1-2 GHz), WLAN (2.4 GHz), WiMAX (3.5 GHz), C-band (4 GHz), WLAN (5.2 GHZ), and some part of 8 to $12 \mathrm{GHz}$, including X-band satellite communication applications.

Table 2: Summary of the structural and performance features of the antenna in this work and antennas in [1-10].

\begin{tabular}{|c|c|c|c|c|}
\hline Ref & Size $\left(\mathrm{mm}^{2}\right)$ & Operating bandwidths & Peak Gain (dB) & Efficiency \% \\
\hline [1] & $122.5 \times 60$ & $\begin{array}{l}\text { GSM900/GSM1800/GSM1900/ } \\
\text { LTE2300/LTE2500 }\end{array}$ & $\begin{array}{c}0.62-2.12 / 2.38-3.81 / 3.82- \\
4.79\end{array}$ & $42-54 / 45-71 />53$ \\
\hline [2] & $120 \times 60$ & $\begin{array}{c}\text { GSM850/GSM900/DCS1800/PCS1900/UMTS/ } \\
\text { TDSCDMA/LTE2300/ } \\
\text { WLAN }\end{array}$ & $0.96-2.4 / 3.2-4.5$ & $50-76 / 57-84$ \\
\hline [3] & $80 \times 60$ & $\begin{array}{l}\text { GSM900/DCS1800/LTE2300/ } \\
\text { LTE2600 }\end{array}$ & $3.0-4.0$ & $85-95$ \\
\hline [4] & $\begin{array}{c}\text { Ground: } \\
260 \times 200 \\
\text { Antenna: } \\
83 \times 6\end{array}$ & $\begin{array}{l}\text { GSM850/GSM900/DCS/PCS/ } \\
\text { UMTS }\end{array}$ & $1.06-1.3 / 2.15-2.44$ & $70 / 74$ \\
\hline [5] & $40 \times 40$ & $\begin{array}{l}\text { WLAN5.2/WLAN5.8/WiMAX2.5/ } \\
\text { WiMAX3.3/ WiMAX5.5 }\end{array}$ & $4.5 / 4 / 8.1$ & - \\
\hline [6] & $45 \times 40$ & $\begin{array}{c}\text { WLAN2.4/WLAN5.2/WLAN5.8/ } \\
\text { WiMAX2.5/WiMAX3.5/WiMAX5.5 }\end{array}$ & $3.2 / 2.38 / 2.34$ & $76.5 / 69.5 / 61.7$ \\
\hline [7] & $20 \times 20$ & $\begin{array}{l}\text { WLAN2.4/WLAN5.2/WLAN5.8/ } \\
\text { WiMAX3.5/WiMAX5.5 }\end{array}$ & - & - \\
\hline [8] & $20 \times 20$ & $\begin{array}{c}\text { WLAN2.4/WLAN5.2/WLAN5.8/ } \\
\text { WiMAX2.5/WiMAX3.5/WiMAX5.5 }\end{array}$ & $1.2 / 1.9 / 2.1 / 3.6 / 4.8$ & - \\
\hline [9] & $14 \times 14$ & $\begin{array}{l}\text { DCS/GSM 1800/ WiMAX 3.5/ } \\
\text { WLAN } 5.2\end{array}$ & 2.7 & - \\
\hline$[10]$ & $25 \times 25$ & WiMAX/WLAN & $0.84 / 1.09 / 0.89 / 1.08$ & - \\
\hline $\begin{array}{c}\text { This } \\
\text { work }\end{array}$ & $14 \times 14$ & $\begin{array}{c}\mathrm{L} \text { band/ WLAN2.4/WiMAX3.5/C band/ WLAN } \\
\text { 5.2/WLAN 5.8/ITU } 8 \mathrm{GHz} / \mathrm{X} \text { band }\end{array}$ & $0.3 / 0.9 / 0.95 / 1.7 / 2.2 / 1.9$ & $\begin{array}{c}73 / 49 / 73 / 81 / 81 / \\
87 \\
\end{array}$ \\
\hline
\end{tabular}

\section{Comparison}

To shed light on the advantages of the proposed design in comparison with some of the previously designed structures, Table. 2, summarizes the characteristics of the antenna in this work and the antenna designs in [1-10]. As can be seen, the proposed antenna has the most compact size among the antenna except for the antenna in [9] which is as large as this antenna. Also, gain and efficiency values are included in the table which shows the suitable performance of the proposed antenna. Although having a

\section{Conclusion}

A compact L-strip coaxial-fed line antenna is proposed for multiband applications. The several resonances that are excited by the constituent L-shaped elements yields a multiband functionality. The obtained frequency bands include $230 \mathrm{MHz}$ (1.19-1.42 GHz), $280 \mathrm{MHz}$ (1.70-1.98 $\mathrm{GHz}), 320 \mathrm{MHz}(2.19-2.51 \mathrm{GHz}), 680 \mathrm{MHz}$ (3.14-3.82 $\mathrm{GHz}), 380 \mathrm{MHz}(4.10-4.48 \mathrm{GHz}), 530 \mathrm{MHz}(5.07-5.60$ $\mathrm{GHz}), 1310 \mathrm{MHz}(7.23-8.54 \mathrm{GHz})$, and $1150 \mathrm{MHz}(9.48-$ $10.63 \mathrm{GHz})$ to cover the L-band $(1-2 \mathrm{GHz})$, WLAN $(2.4$ 
GHz), WiMAX (3.5 GHz), C-band (4 GHz), WLAN (5.2 GHZ), and some part of 8 to $12 \mathrm{GHz}$. Furthermore, the far field radiation patterns are mostly omnidirectional at all operation bands. The obtained results show that the reported antenna has acceptable performances for multiband applications.

\section{References}

[1] Y.J. Chou, G.S. Lin, J.F. Chen, L.S. Chen, M.P. Houng, Design of GSM/LTE multiband application for mobile phone antennas, Electron. Lett., 51: 1304-1306, 2015.

[2] D. Wu, S.W. Cheung, T.I. Yuk, A compact and lowprofile loop antenna with multiband operation for ultrathin smartphones, IEEE Trans. Antennas Propag., 63: 2745-2750, 2015.

[3] Y. Yang, Q. Chu, C. Mao, Multiband MIMO antenna for GSM, DCS and LTE indoor applications, IEEE Antenna Wireless Propag. Lett., 15: 1573-1576, 2016.

[4] H.W. Liu, C.F. Yang, Miniature multiband monopole antenna for WWAN operation in laptop computer, Electron. Lett., 46: 21-23, 2010.

[5] A. Sharma, P. Ranjan, R.K. Gangwar, Multiband cylindrical dielectric resonator antenna for WLAN/WiMAX application, Electron. Lett., 53: 132-134, 2017.

[6] H. Huang, Y. Liu, S. Zhang, S. Gong, Multiband metamaterial-loaded monopole antenna foe WLAN/WiMAX applications, Antenna Wireless Propag. Lett., 14: 662-665, 2014.

[7] P. Beigi, J. Nourinia, Y. Zehforoosh, B. Mohammadi, A compact novel CPW-fed antenna with square spiralpatch for multiband applications, Microwave and Opt. Technology Letters., 57: 111-115, 2015.

[8] P. Beigi, J. Nourinia, A novel printed antenna with square spiral structure for WiMAX and WLAN applications, ACES journal., 30: 1329-1333, 2015.

[9] P. Beigi, P. Mohammadi, A novel small triple-band monopole antenna with crinkle fractal-structure, Int. J. Electron. Commun. (AEU)., 70: 1382-1387, 2016.

[10] J. Pourahmadazar, Ch. Ghobadi, J. Nourinia, H. Shirzad, Multiband Ring Fractal Monopole Antenna for Mobile Devices, Antenna Wireless Propag. Lett., 9: 863-866, 2010.

[11]R. Sonak, M. Ameen, R.K. Chaudhary, Triple Band Omnidirectional Miniaturized Metamaterial Inspired Antenna Using Flipped Rectangular Stub for LTE, WiMAX, and WLAN Applications, International Journal of RF and Microwave Computer-Aided Engineering., 1-9, 2019.

[12]R.K. Saraswat, M. Kumar, A Metamaterial Hepta-Band Antenna for Wireless Applications with Specific Absorption Rate Reduction, International Journal of RF and Microwave Computer-Aided Engineering., 1-12, 2019.
[13] P. Beigi, Y. Zehforrosh, M. Rezvani, J. Nourinia, Evaluation of A Compact Triangular Crinkle Shaped Multiband Antenna with Circular Polarized for ITU Band Based On MADM Method, Circuit world., 1-9, 2019.

[14]D. Kaushal, T. Shanmuganantham, Design of A Compact and Novel Microstrip Patch Antenna for Multiband Satellite Applications, Science Direct: Proceedings 5., 21175-21182, 2018.

[15] K. Srivastava, A. Kumar, B.K. Kanaujia, S. Dwari, S. Kumar, Multiband Integrated Wideband Antenna for Bluetooth/WLAN Applications., Int. J. Electron. Commun. 89: 77-84, 2018. 